\title{
Malagasy Conservationists and Environmental Educators: Life Paths into Conservation
}

\author{
Lena M. Reibelt ${ }^{1,2, *}$, Torsten Richter ${ }^{1}$, Antje Rendigs ${ }^{2}$ and Jasmin Mantilla-Contreras ${ }^{1}$ \\ 1 Department of Biology, Research Group Ecology and Environmental Education, University of Hildesheim, \\ Universitätsplatz 1, 31141 Hildesheim, Germany; richtert@uni-hildesheim.de (T.R.); \\ mantilla@uni-hildesheim.de (J.M.-C.) \\ 2 Madagascar Wildlife Conservation, Lot 17420 bis Avaradrova Sud, 503 Ambatondrazaka, Madagascar; \\ antjerendigs@posteo.de \\ * Correspondence: reibelt.lena@gmail.com; Tel.: +49-5121-88340440
}

Academic Editor: Ralf Hansmann

Received: 20 December 2016; Accepted: 1 February 2017; Published: 8 February 2017

\begin{abstract}
In a globally fast-changing world, dedicated conservationists play a central role in societies moving towards the achievement of sustainable development. How do people become advocates for nature? Research suggests that childhood experiences in natural places are core determinants for the development of environmental stewardship. In many developing countries, however, access to intact natural environments is limited. This study explores formative influences on individuals who actively contribute to nature conservation and environmental education (EE) in Madagascar. We conducted nine semi-structured interviews with participants in a national EE workshop. Formative experiences were reported mainly from university years, and influential persons were researchers and high school teachers, many from abroad. The media also play a considerable role, while negative experiences, familial influences, or experience of natural areas during childhood were rarely mentioned. In contrast to former studies, the results suggest that direct experiences of nature can still be decisive in determining a young person's path as a dedicated environmental practitioner during young adulthood. Role models who are active in the conservation and sustainable development fields can compensate for a lack of familial models. These findings might require a rethinking of current educational practices in Madagascar because children might not be the only important group to target with educational interventions.
\end{abstract}

Keywords: significant life experiences; formative events; environmental education; nature conservation; environmental awareness; values

\section{Introduction}

To support the efforts towards global sustainable development, there is an increasing need for dedicated conservationists and educators worldwide. This leads to the question of what kinds of experiences are key to the formation of advocates for the environment. A wealth of research has been done on significant life experiences, also called formative events. This research is based on participants' memories; they share the experiences they consider important in retrospect, be it their choice of conservation work [1,2], attitude towards the environment [3], interest in or concern for the environment [4], or commitment to environmental protection [5]. All studies found similar patterns: time spent outdoors or in pristine environments during childhood seems to be one core determinant for developing interest in the natural environment and its conservation. To date, all studies on formative life events have supported Tanner's hypothesis that a child must first come to know and love nature before he or she can develop concern for its state or the wish to care for it [1]. During our research on environmental education in Madagascar, however, personal communications suggested that most 
Malagasy do not have the opportunity to experience pristine nature and form positive bonds towards it during childhood.

With its high rates of plant and animal endemism, Madagascar has been identified as one of the "hottest hotspots for biodiversity" [6]. At the same time, natural forests and biodiversity are increasingly threatened, and destruction of natural habitats, ecosystems, and forest patches are a daily occurrence. The subsistence needs of local farmers are one of the reasons why natural areas are transformed into agricultural land. Madagascar figures amongst the poorest countries in the world, ranking 154th out of 188 countries listed on the Human Development Index, a composite measure which includes health, education, and living standards: of the 23 million inhabitants, $88 \%$ live below the poverty line of 1.25 USD a day and many depend on subsistence agriculture [7]. The consequences of colonization and the malgachisation of teaching (an attempt to eradicate post-colonial influences with the abolition of the French language, and the introduction of an official Malagasy language, which resulted in the severe deterioration of the quality of schooling; for further details see [8], and references therein) are still present in the school system, which struggles to educate the Malagasy. Fifty-eight percent of youth aged between 15 and 24 have not completed primary education, and only $2 \%$ are enrolled in post-secondary education [9]; most worrisome, only $19 \%$ of primary school teachers are trained to teach [7]. The island has received extensive international donor attention [10] in an attempt to end poverty, improve education, and protect wildlife and ecosystems. To date, however, the rampant poverty levels still undermine conservation efforts in the country. Recent studies showed, as expected, that locals value subsistence and agricultural output over conservation [8,11]. One of the reasons, other than poverty, for this attitude is that most Malagasy aren't aware of the biodiversity and conservation values of their country.

As an example, in the Lake Alaotra region of Madagascar, primary school teachers were asked about the environmental problems in their neighbourhood. They were rather concerned about the social environment, and were interested in natural issues only when these had direct implications for agriculture or other (immediate) livelihood issues [8]. Due to the teachers' lack of knowledge and awareness of environmental problems and their causes, the regional ecosystems and endemic species are not addressed in most primary schools in the region. Despite the vicinity of lake and marshes, most school children have never seen the locally endemic flagship species Hapalemur alaotrensis. An evaluation of the environmental education programme by Madagascar Wildlife Conservation revealed that less than a fourth of primary school children had ever seen a lemur. This number already included children who had seen lemurs in books (18\%), in a zoo (7\%) and as pet lemur (4\%); only $6 \%$ of the participating primary school children had seen a lemur in its natural habitat [12]. Generally, only few Malagasy have ever seen a lemur in the wild [13], and most Malagasy children do not learn about biodiversity at school [14]. Apart from school, non-governmental organizations try to raise awareness about the country's biodiversity and the threats against it. Criticism has evolved that some NGOs might impose western conservation values on Malagasy learners, without acknowledging local and regional ethics and beliefs. Madagascar has a wealth of beliefs, both religious and spiritual. Local and regional taboos, called fady, and the belief in good and evil spirits intervene in daily life [15]. The evil spirits in particular are believed to dwell in the forest, rivers and caves. As a consequence, the environment is sometimes perceived to be "a place of reverence and trepidation" [15]. The combination of subsistence, poverty, and the complex belief system shape the lives especially of rural farmers. This results in a different perception of the environment than that of western conservationists who focus on biodiversity values. In addition, access to both formal and informal education is limited, and awareness of the country's peculiarities is not common in the population. A leading Malagasy primatologist stated that it was not until university that he learned about lemurs [14], and yet he is one of the most dedicated Malagasy researchers and conservationists. Indeed he is not the only one; others work hard to achieve conservation and sustainable development in the country, including environmental education. When thinking of future conservation and education interventions in 
Madagascar, what kind of capacity building interventions could have the most impact while at the same time respecting local values and beliefs?

Previous studies suggest that childhood play in natural settings is one core determinant to develop interest or stewardship for the environment $[1,4,5]$. These studies were all conducted in industrialized, Western countries. In view of the discrepancy between available research on formative events and the information we obtained from personal communications in Madagascar, we were interested to see whether the practitioners in Madagascar had any formative experiences other than childhood play in natural settings. We aimed to find out how and why they became advocates for the environment in order to possibly inform the conservation and sustainability sector about measures which might be taken to increase environmental awareness in future.

A review of the existing literature on formative life events for conservationist careers showed the publications by Chawla $[5,16,17]$ and Palmer and Suggate [18] to be of particular use for our study. Chawla [5] provides an elaborate presentation of the eleven distinct categories she used for her study sample of 56 environmentalists from Kentucky, USA, and Norway. She found that, similar to other studies, childhood experience was the most important source for the environmental commitment of her study participants. More than half also mentioned family and organizations, while negative experiences such as the destruction of nature, and education or the influence of friends were mentioned by more than a third to have played a crucial role. Less than 30 percent mentioned vocation, a sense of social justice, a book or an author, principles or religion, or concern for (grand) children (for explanations of the categories, please see Appendix A). While categories varied, similar patterns have been reported by various studies from other high income countries (e.g., [1,4,18]). Chawla [5] further found that some individuals' actions were driven by love of nature, while James found that more than half of his sample $(n=50)$, who were Americans with multiracial backgrounds, mentioned job opportunity as a reason for their career choice in environmental education [2] (as cited in [5]). This was in line with an earlier finding that individuals' life courses are a mixture of personal interests and the opportunities life offers; these sometimes change interests and can turn people's energies in new fields and directions [19]. Based on these insights, we developed our semi-structured interview guide; a description is provided in the methodological section.

Research continues to address the question as to what formative childhood experiences determine environmentalism in adulthood (e.g., [20-22]). Bearing in mind the different cultural, educational, and economic context in Madagascar, it is important to ask what pathways into conservation and environmental concern exist in the country. In this explorative study we aim to identify the formative experiences and persons Malagasy conservationists judge important in retrospect.

\section{Materials and Methods}

Structured open-ended interviews were conducted during a national meeting of leading Malagasy conservationists and environmental educators in Toamasina in 2015. We conducted one-to-one interviews of about $30 \mathrm{~min}$ in length (min. 19, max. 46) with 9 workshop participants. Study participants were chosen based on the recommendation of a leading conservationist, and availability. The interview guide contained an introductory section with background questions on age, gender and level of education; the open questions asked for formative experiences and persons, whether their choice to work for the environment was driven by love of nature, and whether they had entered their profession by chance or active choice. The interviews were conducted in French by the first author, and informed consent was obtained prior to audiotaping. The interviews were transcribed and then analyzed with MaxQDA 11, also by the first author who had spent extensive periods in the field, first-hand experience of the context being crucial for a holistic understanding and interpretation of the interview statements. The statements that are shared in this manuscript were translated into English after the analysis had been completed, and only slightly edited to preserve their character and ensure reliability and authenticity of our results. 
Analysis was based on a categorical system that was established by using both an inductive and deductive coding approach $[23,24]$ in an iterative process. We considered the categories found in reviewing the literature on significant life experiences; a main critique of former studies was that they did not produce comparable results due to inconsistent categories of analysis [16]. Based on our data, we decided to follow the categorical system and code definitions of Chawla [5], which are based on an extensive review. To better represent our data, while still ensuring comparability, we added further categories as listed in Appendix A. We ensured reliability in our study by being conservative in interview analysis [1], i.e., by "scoring only those responses to which explicit or prominent references were made" [4] (p. 27). In the results section, descriptive statistics (mainly percentages) are used to present the number of mentions of each category, and subsequently, exemplary citations from the interviews are given.

\section{Results}

The age of the participants ranged from 25 to 62 years; two were below 30, four below 50, and three were older than 50 . Of the 5 men and the 4 women, the lowest educational degree was a high school diploma (1), the highest was a post-doctoral qualification (1); the remainder were PhDs (2) and Masters (5) in Plant Biology, Anthropology, Geography, Agronomy, and Conservation Biology. The range of mentioned formative aspects was 1 to 5 (median 2); when including multiple mentions, the range was 2 to 7 (median 3); all participants thus mentioned several sources for their interest in the natural environment.

\subsection{Main Stimuli that Awakened Interest in the Natural World}

The one main influence that Malagasy conservationists and environmental educators recall is education, which comprises the influence of educators and field trips. Other major influences are the media, i.e., books and television, and travel. Organizations, negative experiences, friends, and social justice were mentioned by one fifth. The data are summarized in Table 1 and showcased in more detail in the following sections.

Table 1. Sources of interest in the natural environment mentioned by Malagasy conservationists and environmental educators (\% mention rate; $n=9$ ); categories based on Chawla [5] and Palmer and Suggate [18] *.

\begin{tabular}{lc}
\hline Sources & Mention Rate (\%) \\
\hline Education & $\mathbf{7 8}$ \\
Setting/field trip & 78 \\
Persons & 67 \\
Media & $\mathbf{4 4}$ \\
Book or author & 33 \\
Television & 22 \\
Travel & $\mathbf{4 4}$ \\
Organizations & $\mathbf{2 2}$ \\
Negative experiences & $\mathbf{2 2}$ \\
Habitat destruction & 22 \\
Pollution, radiation & 0 \\
Friends & $\mathbf{2 2}$ \\
Sense of social justice & $\mathbf{2 2}$ \\
Family & $\mathbf{1 1}$ \\
Parents & 0 \\
Others & 11 \\
Experience of natural areas & $\mathbf{1 1}$ \\
Concern for (grand)children & $\mathbf{1 1}$ \\
Vocation & $\mathbf{0}$ \\
Principles or religion & $\mathbf{0}$ \\
\hline
\end{tabular}

* The main categories are shown in bold, sub-categories in italics; see Appendix A for definitions of the categories. 
Education. This aspect influenced $78 \%$ of study participants. More specifically, field trips during university courses were considered by $78 \%$ to be crucial for the development of interest in the natural world, as exemplified by the following two statements:

"I remember it was especially during my university studies, [ ... ] when I was in the 4th year, they took me to travel in the forest of 'Montagne d'Ambre' [National Park] and I believe this is the experience in the environmental domain that I liked the most in my life, because it's discovering something else, discover forests, waterfalls especially, and the sea. It is then I think where I started to love nature."

"When I was in the second year, we made an excursion to Andasibe [National Park]. And this was the first time in my life that I saw the lemurs in their natural habitat. And one of our professors explained a lot, the role of lemurs, their importance, and from then on, I started to be interested in biodiversity, especially the endemic biodiversity of Madagascar."

One participant specified that the confrontation with reality was an awakening experience:

"It started in 1999, we finally went to university, I was already in the department of Palaeontology, we learned... but... the fact of going into the field to see the things in the forest, that's different. Learning theoretically, and seeing reality, that made the difference. Yes. Because we learned as in school to get good grades and to pass exams and that was the most important thing before. But after this experience it was different."

The above are examples of statements showing that most participants judge excursions during their studies at university as crucial for their love of and interest in the environment. Only one participant remembered an influential nature experience during primary school; he described the excursion they went on at the end of each school year:

"I remember I enjoyed it, because when we had an excursion or picnic we used to come to a place like that [picnic area with tree plantation]. So I feel, I saw the difference like coming from town to go to a place like that, even if it's not too far from Tana [the capital Antananarivo]. But I've noticed there is a big difference, much better air you can get and the fresh water, just to see that. So I started to be more interested in that."

Sixty-seven percent mentioned inspiring teachers who influenced their interest in the natural environment. Interestingly, amongst the influential persons, a remarkable proportion comprised foreign researchers $(44 \%$, or $67 \%$ of the sub-sample).

"People from Missouri Botanical Garden. They are international researchers, such as Dr. Chris Birkinshaw, Dr. Pete Lowry, mainly these two persons."

"Patricia Wright was among the people who influenced me. She discovered new species and has always talked about this discovery of new lemur species, so it is really something to discover!"

"It was especially Alison Jolly, but later it also was the passion of the students, and their involvement. This pushed me further. Because when I saw that they were interested, that pushed me even more to get involved with them, to continue, thus supporting all their actions."

One interviewee aimed at becoming as popular as the role models:

"I had fallen in love with lemurs, not only their beauty, but their importance too, so when I learned the importance of primates, I thought: for the pioneers for the gorillas, it was Dian Fossey, for the pioneers of chimpanzees it is Jane Goodall, and in Madagascar it was Allison Jolly. And I dream for me, wow, why not, one day, I will be famous too, not just famous, but somebody important contributing to the conservation of biodiversity." 
Similarly, another person was inspired to contribute to research as an independent individual in a leading position.

"I was a student at a non-governmental organization when I made my DEA [equivalent to Master's degree] and there we communicated with international researchers and I said to friends and colleagues, 'I'm Malagasy, so when I do my research, I'd like to become the investigator one day but not always only the assistant'. It is like a challenge."

The remaining 22\% (33\% of the sub-sample) mentioned Malagasy professors, and one interviewee mentioned a guide in a National Park who worked with the university:

"There was someone who was a guide in Masoala at that time. And he knew all the species, but only their name in Malagasy, and he taught us a lot [ ... ], he opened us towards other species, the lemurs and frogs, and all this, and what I remember very well of him, he taught me the smells of the forests, and also the noise and he told me when the birds stop singing, that it will rain [ ... ]. And he also taught me that when the frogs are croaking, it means that the weather will be fine and you can stay as long as you want to in the forest. I think he really is an expert, but with his local knowledge, not translated into scientific knowledge."

All participants mentioned several influential persons (range 2-4); if multiple mentions are included, the percentage of influential teachers increases from $78 \%$ to $189 \%$. Of these, $44 \%$ were non-countable mentions, e.g., international researchers, foreign students, or tourists.

Media. The second most important significant influence on our sample was the media (44\%) which includes books or magazines (33\%) and television (22\%). For example:

"I think the one experience that I got is when I went to the library and was just reading a book containing all the stuff that I saw for the first time; to see all the animal pictures and plant pictures sparked my interest in nature because I never had the opportunity to get to a forest when I was in Tana [ . . . ]. And after that I tried to, want more, to see animal reports, documentaries, to try to ask my mum to take me to the zoo or something like that."

"When I was little, I was already interested in the environment, it was already something I was passionate about, I love nature and everything. I liked books very much already, but there was the magazine 'Vintsy', so I learned a lot from this magazine."

Travel. In our study, $44 \%$ mentioned having visited one to three foreign countries during their studies and career. All but one stated directly or indicated indirectly that they had travelled a lot in Madagascar thanks to their profession. Two examples of trips abroad and their impact are provided below:

"And then in the fourth year I participated in the TBA, Tropical Biology Association field course and I was in Uganda, and there too we learned a lot of things, biodiversity of Africa in general, plants and all that, and that also prompted me to become responsible because the endemic biodiversity belongs to Madagascar and as I'm Malagasy, I feel responsible to participate in the conservation of Madagascar."

“When I was a child, I was afraid of animals. I was afraid of chickens, cats, yes. That's among the Malagasy, most Malagasy are afraid of animals. But when I was 19 years old I went to Russia [ ... ] to learn breeding of domestic animals. And it's there I learned to love animals."

Organizations. Two participants described how the active involvement in a specific NGO allowed them to develop and broaden their interest and knowledge of the environment.

Negative experiences. Reports of negative events were low (22\%). 
"In the Department of Paleontology, we were looking for fossils, we went to the forest and we found traps, captured lemurs in the traps ... so that's urgent. It was necessary to 'switch', i.e., the fossils can wait in the ground and we must save the living."

"Seeing the degradation that exists all around in our environment. After that, it was from reading books, as I said."

Friends. These were influential for $22 \%$, e.g., in the choice of specialization, and during the course of studies:

"When I was in the fourth year it was peer influence. It's very weird. So, my friends were saying "Ah, I'll do this, I'll do that, and you, what are you going to do?'. It's not, what do you WANT to do, but what WILL you do. And everyone said that botany is interesting and afterwards there is something to do and I chose botany."

“We were a group, a group of young students. We were five people, each one with his specialization, the lemurs, reptiles, birds and all that, who formed a group. And I met these passionate people around me who gave me courage, and who made me love the profession we do."

Social justice. Two interviewees stated that they were concerned about the wellbeing of the Malagasy population, and that conservation work was a means to improve their lives:

"I'm not a pure conservationist to say: the plant is the most important thing, it is not that. For me, if you are studying plants, to do plant conservation, it is mainly for humankind. So I started to think that working in environmental conservation, plant conservation, is for human development."

"In fact what I wanted to do was rural development. I didn't and don't want to leave the rural setting, but to improve it. And that's why I chose agronomy as my field of study. Because most of the time the farmers, the rural people, they are poor."

Family. Not a single interviewee mentioned their parents as having awakened their interest in nature; one of the younger participants even stated:

"No, on the contrary, people tried to influence me to choose another field such as medicine, but I was not interested in that."

Furthermore, studying the natural environment or animals did not have a good reputation until some years ago:

“My parents don't have any background at all regarding animals. By the way, before, in Madagascar, studying animals ... this was silly, especially the animals of the forest. I still remember that there were situations when we talked about the forest: these are bad things, bad spirits, so working in the forest that's where there are bad spirits. It was not my parents but in general people talked like that."

An influential nature experience during childhood was described by one study participant:

"And then my parents, during holidays, we did not travel, but we went to the countryside, and one does not have this feeling of being enclosed in a house, in a yard, but one has the feeling of being free. It may be this that I liked back then and what I later found in the forest again... as we were so free."

One participant, a parent, was concerned about the children of tomorrow: 
"It is for love, and... well, it is in view of the situation [ ... ]. I said: oh, what is the future of the next generation? So, in view of the state of biodiversity, what needs to be done, so there is a very urgent need to conserve that."

As specified in Appendix A, the definition of the category "experience of natural areas" excluded one-time stays of adults, but focused on childhood experience and regular leisure time activities only. We were tempted to broaden the definition, but retained it for comparability reasons. However, to cover the excluded aspect as well, we re-analyzed the data with a broader definition of nature experience, including all stays in natural settings, also non-regular exposure to natural surroundings in adulthood. With this categorization, a majority $(78 \%)$ of our sample had intense experiences of nature, either during their university studies, or in research projects shortly thereafter, i.e., all during young adulthood.

\subsection{Choice of Profession}

Independent of influential experiences and persons, interviewees were also asked whether their choice to work for the environment was driven by love of nature. Fifty-six percent stated that love of the environment had influenced their career choice:

"I think it really was love of nature and a vision of freedom I have in nature. And it is later that I began to understand that people depend on nature. The value of biodiversity, the practical value of biodiversity and everything, that everyone, all life depends on biodiversity."

The remaining $44 \%$ ascribed their choice not to love of nature, but to the following:

"As I said before, there was already this passion, so maybe it was pushed by the context I was following, developing awareness, so more passion and more awareness."

"A combination of two things. Even if it is not by love, but by conviction [ ... ] and by seeing the reality of the people."

"Love of my home country. Love of country, because the country is really the people, the population [ ... ]. Everything together, not only nature, but all together."

We also asked whether the choice of their profession had been an active choice or whether they entered this path by chance. Sixty-seven percent stated that it had been an active choice to enter the environmental field, while for $33 \%$ it was by chance:

"Well, it's a bit difficult to explain this, but you know in Madagascar, opportunities for work are very limited. So you have to take the opportunity if there is one. You have to love and you must develop it."

\section{Discussion}

This study provides a first explorative assessment of formative experiences that awakened the interest of Malagasy individuals in nature. The data presented here showed similarities with results presented in former studies but some striking differences were also revealed by the current research. Education was ranked as the one main influence. The minor role of childhood natural area experience was surprising, as was the fact that family was not given a dominant role by the participants of this study. On the contrary, family influence was negative in some cases or the family tried to discourage the individual from seeking a career in conservation. These outcomes stand in contrast to many former studies that identified nature experience in childhood and influence of parents as determinant factors $[1,4,5,16,18,21]$. 


\subsection{Higher Education Offers New Perspectives}

Field trips in the second or fourth year of university studies were formative experiences for the majority of the Malagasy interviewees independent of their study subjects, which ranged from Anthropology to Geography. Some participants mentioned that they did not learn about lemurs or the biodiversity of Madagascar until they went to university, a fact also mentioned by Ratsimbazafy [14]. Similarly, Palmer [4] found that for some participants in her study, a concern for the environment did not develop until they participated in higher education and adult courses.

At the same time, teachers in the broader sense played an important role as well. In our study sample, the main influences seem to come from foreign researchers who are working in Madagascar. Collaborations of foreign researchers with Malagasy universities offer the funding and opportunity for students to learn and gain experience in the field and to travel, i.e., to get to know new perspectives. These collaborations also include contact with western researchers and their values. The influential Malagasy role models were mostly teachers at university who were in regular contact with foreigners, or had lived abroad for some time.

Since Madagascar's independence in 1960, external donors and conservationists have continued to shape policies, projects and decisions [10]. Many foreign NGOs support and implement conservation and development programmes. Criticism has evolved that the activities promote western values rather than incorporating local knowledge, needs, and values. Given the high importance that participants of the present study give to foreign researchers and conservationists, we call for a more elaborate view. We agree that top-down conservation which imposes western goals on local communities is not the way to go [25-27]. However, we still think that Madagascar can profit from external, pro-conservation perspectives. These might broaden knowledge, approaches, and (funding) opportunities, and finally facilitate the formation of a "Malagasy way" towards a sustainable balance between conservation and development. Some participants of this study described how their travelling to other countries has changed their awareness and attitude towards the biodiversity, the endemic plants and animals of their own country. The trips within the country also helped to broaden their horizons, and to help them get to know what the island originally looked like.

To make our point clear, we further stress that the role of family or parents in our sample is non-existent. Studies from industrialized Western countries found that attitudes and actions of family members were crucial to develop interest or positive attitudes in nature [4]. If family attitudes are crucial, it is worth taking a closer look at the social and cultural constructs in Madagascar. For the general public, the natural environment does not seem to carry positive connotations; forests are widely considered to be ominous places where bad spirits may wait for visitors [15]. Some forest animals such as the lemur species Daubentonia madagascariensis or Aye-Aye is believed to bring evil (mostly disease or death to someone in the village it enters or passes), and is often killed when seen to fight the bad fortune it is believed to bring to people [28]. In the South, the tortoise Geochelone radiata is fady, i.e., consumption is prohibited by a taboo, because it is considered dirty by the local people [29]. Depending on the region, different lemur species are fady and not allowed to be eaten, e.g., Indri indri, or Propithecus verreauxi [30], and chameleons generally have a status between being respected and feared on the island, because they are considered to be connected with powerful spirits [31]; for an overview of good and bad spirits and their connections with Zanahary (God), see [15]. Each region has different fady, but due to migration, taboos are followed less and less today. While immigrants do not generally follow the local fady, respect for the ancestors still sustains many of the taboos. The ancestors generally play an important role in daily lives, and the social system is hierarchical, i.e., ancestors are the most powerful, while the elders are the leaders of communities and can act as a communication channel between people and their ancestors. Younger persons are not in a position to question or criticize older persons or traditional practices. For traditional people, changing their way of living would be an insult to their ancestors (which these may punish in consequence). With increasing migration, travel activities, and visits by foreigners, existing traditional worldviews may be increasingly questioned. 
This can have implications for conservation issues, but more essentially cause change in Malagasy society. This is a struggle which especially the younger generations will have to deal with.

\subsection{Several Day Excursions as Transformative Experiences for Young Adults}

Memorable experience of natural areas as defined by Chawla [5] was only shared by one person, who experienced a feeling of freedom during her childhood visits to the countryside. Chawla \& Cushing [32] reviewed several studies and summarized: "from half to more than $80 \%$ of the respondents identify childhood experiences of nature as a significant experience, such as free play, hiking, camping, fishing and berry picking" (p. 3). None of these activities were mentioned by our respondents.

However, our study revealed that a majority of our sample had intense experiences of nature in young adulthood. The participants vividly described how these experiences changed their way of looking at the world. In Madagascar, more or less intact ecosystems are mostly restricted to protected areas such as National Parks that most Malagasy people do not have the opportunity to visit. Giving the young people the opportunity to experience a stay in these pristine environments seems to be a crucial game changer in Madagascar. This point of view was also shared by Palmer and colleagues [33] who stressed the "overall tremendous importance of direct experiences in the natural world" (p. 454). Many previous studies have identified childhood experience of natural areas as crucial experience (e.g., $[1,4,5,16,33])$. Our study did not confirm this for the Malagasy conservationists. However, despite the lack of such childhood experiences, they are actively involved in conservation and environmental education activities. Our study suggests that the experience of pristine nature can still have tangible effects in young adulthood.

Both education and nature experience during adulthood amount to $78 \%$. Basically, these categories are almost congruent. This reflects reality in Madagascar; most Malagasy children and adults do not have access to experiences in natural environments or parks for financial reasons, i.e., they can afford neither transportation costs, nor entrance or guidance fees. Furthermore, the value of visiting such places is not promoted as it is in western culture. The environment is regarded from an anthropogenic perspective by most Malagasy who depend on subsistence agriculture [8]. However, our study participants all belong to the $4 \%$ who finish secondary schooling, and who have the chance for in-depth studies and are therefore part of a small educational elite. Similarly, the ethnicity of American Middle school students and the income of their counties influenced their environmental knowledge levels [34]. Our study participants are an exception in the country in that they had the opportunity to participate in trips to pristine nature areas. Besides their educational levels, their economic status allows them to make a choice.

\subsection{Negative Experiences}

Negative experiences did not figure prominently in our sample. This comes as a surprise, as the majority of forests in Madagascar have been destroyed and have changed into large landscapes covered by infertile dry grasslands, and erosion gullies are a common feature of hilly landscapes. Thus, the destruction of the natural environment is pervasive. However, for most people, the agricultural environment is the only "natural" environment they know. Moreover, this lack of negative experience may be explained by the fact that most study participants were from the capital, far away from forests. A study in villages around the National Park Ranomafana suggested that pupils who lived close to recently deforested areas were more aware and concerned about environmental destruction than children from forested areas. On the other hand, the closer children lived near the National Park, the more aware of environmental destruction they generally were [35], probably due to increased educational interventions. A similar pattern was found around Lake Alaotra, where local resource users' environmental knowledge and awareness levels decreased with increasing distance to a special conservation zone [11]. Chawla [16] hypothesized that future activists may mention childhood experiences as a formative factor less and less as time passes, due mainly to a decreasing availability 
of natural places. At the same time, it was suggested that negative experiences as motivating factors would increase $[16,18]$. Our study does not confirm this. Childhood experiences do not play a major role in the examined context, nor do negative experiences figure among the prominent reasons for becoming interested in the natural environment. Further surveys are needed to assess whether the virtually inexistent mention of childhood experience in Madagascar is related to cultural or historical reasons, or whether this is related to the "new generation" of activists that were predicted by previous publications. The good news, however, is that advocates for the environment can also develop without these childhood experiences.

\subsection{Working for the Environment: between Vocation and Chance}

Reasons and motivation for working for the environment varied in our study. For some participants it was an opportunity to earn money, and some had entered the profession by chance. James [2] (as cited in [15]) conducted interviews with environmental educators from multiracial backgrounds to understand the reasons for their career choice. He was the first to introduce the category "job opportunity", which ranked second after outdoor experiences and mentors. While this was also mentioned in our sample, somewhat more than half of the participants still stated that they had made an active choice. They were motivated to very passionate about their work and some would not want to do anything else. The beginnings of that passion lay in childhood for some, while others described how, step by step, they had become more and more involved. Bandura [19] said that personal life paths are shaped by chance encounters that may change people's interests and activities. Chawla [5] affirmed this finding in her study. She wrote about the participants: "As they took advantage of these opportunities, they developed new skills and beliefs, which sent them off in yet new directions, and so on. What may have first been chance became a foundation for continuities in attitudes and behavior, which determined responses to new chances" (p. 17). This interplay between interest, chance, and passion was also described by some of the individuals in the present study. To better distinguish and interpret the formative influences, future research in Madagascar should also include an assessment of the pro-environmental action and behaviour interviewees are involved in, as for example done by Palmer and colleagues [33]; this would help to assess individual levels of motivation and involvement (cf., $[4,16])$.

Organizations did not figure prominently in Table 1 because of rigorous analysis [1,4]. However, from the descriptions during the interviews it was obvious that some of the formative experiences would not have been possible without certain nongovernmental organizations, e.g., research field trips, or university collaborations with external researchers and NGOs. For some participants, the organizations offered the chance and opportunity to learn about Madagascar's biodiversity, to become interested in nature, and finally to become active for the environment. However, the fact of learning about local biodiversity, or participating in an environmental education programme alone does not determine such trajectories [12]. In this study, pupils who participated in an extensive environmental education comic book project by a German-Malagasy NGO were asked about career preferences. The results collected in rural primary schools of the Alaotra region did not show an increased choice of conservation as a career option by pupils who otherwise longed for academic professions such as teacher or doctor [12]. One possible explanation is the lack of social acceptance of conservation bodies in some villages in that region [27].

\section{Implications for Education and Conservation}

The presented results are based on an exploratory research project with nine Malagasy participants. This number is not representative for the overall conservation and environmental education landscape in Madagascar, but aims to inform future studies with a more systematic approach, i.e., bigger sample size and both qualitative as well as quantitative methods. Future studies need to include participants with different educational background, economic situation, lifestyle, and culture, and consider a possible urban-rural divide. Furthermore, the multifactorial interplay of ecological, economic, and 
social conditions in Madagascar distinguishes this study from past research which focused mainly on western countries. It is hoped that this study will help the topic to receive attention in other developing countries as well.

At first glance, our results may suggest that the more education a child or adult receives, the higher the interest in the environment. On closer examination, however, not the (level of) education is the determinant factor, but the content of education. The (trans-)formative events were real life experiences. Ratsimbazafy [14] specified that very few children knew about "what exists in their backyards (forests), and obviously when they grow up, they do not have an interest in getting involved in saving the endangered biodiversity" (p. 19). This seems to be confirmed by the current study; many participants did not learn about lemurs or biodiversity before university, and most did not place their interest in the environment in childhood. This may be explained by the lack of opportunity for most Malagasy to experience natural areas in private life. This poses a problem for conservation success especially in rural parts, where most pupils only attend primary school [7]. As studies on environmental interventions and nature excursions showed, several-day excursions and hands-on programmes can have a huge effect on participants' knowledge, interest, and attitude (e.g., [36-38]). Our study showed that the university and research experience in nature can be a core element in the development of interest in the natural world. The findings suggest that there is not the one single way to environmental awareness, concern, or activism. Chawla [16] noted that "one conclusive finding of research on responsible environmental behavior is that there is no single all-potent experience that produces environmentally informed and active citizens, but many together. This complexity may make the challenge of EE more difficult, but it also makes it more hopeful. Just as ecosystems are more resilient when they contain an abundance of species that can form diverse adaptations to change, so is the future more hopeful if diverse paths lead people into environmental commitments"(p. 19). Our study results suggest that intense multi-day stays in nature during young adulthood may already have strong transformative potential.

To conclude, we would like to share a statement from one of our study participants:

"The most important experience is, well, to spend time in the forest. To see, to observe, to admire the beauty of nature."

Acknowledgments: We thank the organizers of the workshop and all participants for supporting our research and for contributing to this study; thank you very much for taking time for the interviews, and even more so, for sharing your personal stories with me. The support of Madagascar Wildlife Conservation and GERP is also acknowledged. Thanks to Patrick O. Waeber for support in the study inception phase and questionnaire design, and to Esther van Dijk and Ines Bruchmann for helpful comments on a former version of this manuscript. This work was supported by the Bauer Foundation of the "Deutsches Stiftungszentrum" under grant number T237/22985/2012/kg; the University of Hildesheim is acknowledged for covering the publication fees.

Author Contributions: L.M.R. and T.R. conceived and designed the study. L.M.R. conducted the interviews and analyzed the data. L.M.R., T.R., A.R. and J.M.-C. prepared the manuscript.

Conflicts of Interest: The authors declare no conflict of interest. The founding sponsors had no role in the design of the study; in the collection, analyses, or interpretation of data; in the writing of the manuscript, and in the decision to publish the results. 


\section{Appendix A}

Table A1. Categories for sources of interest in the natural environment, with the respective definitions. Adopted from Chawla 1999 [5] and Palmer \& Suggate 1996 [18] *.

\begin{tabular}{|c|c|}
\hline Category & Definition/ Examples \\
\hline Education & Formal courses or settings. \\
\hline Setting/field trip & Extracurricular activities such as field trips. \\
\hline Persons & Inspiring teachers or educators. \\
\hline \multirow{3}{*}{$\begin{array}{l}\text { Media } \\
\text { Book or author Television }\end{array}$} & Influential books or authors. \\
\hline & Magazines or educational journals. \\
\hline & Television programmes or documentaries. \\
\hline \multirow{2}{*}{ Travel } & Stays in foreign countries. \\
\hline & Trips to distant regions in the country. \\
\hline Organizations & Participation in outdoor, environmental, or social equity groups or associations. \\
\hline $\begin{array}{l}\text { Negative experiences Habitat } \\
\text { destruction Pollution, radiation }\end{array}$ & $\begin{array}{l}\text { Destruction of a favorite natural place. Decline or threat of a species or habitat. } \\
\text { Observation or fear of environmental pollution or radiation. }\end{array}$ \\
\hline Influence of friends & $\begin{array}{l}\text { Influence of peers on choice of profession or field of study. Mediation of job } \\
\text { opportunity or membership in environmental organization by friends. Team spirit. }\end{array}$ \\
\hline Sense of social justice & $\begin{array}{l}\text { Unfair treatment of people, especially the poor and vulnerable. Conviction that } \\
\text { everyone should have access to a healthy environment. Experience of own or other } \\
\text { people's poverty. }\end{array}$ \\
\hline Family & Pro-environmental values cultured by a family member. Environmental \\
\hline Parents & experiences led by or shared with (grand-) parents, or others. Family role models in \\
\hline Others & the areas of social justice or activism. Familial support for environmental efforts. \\
\hline Experience of natural areas & $\begin{array}{l}\text { Valued childhood places. Home or vacation surroundings such as forests, fields, } \\
\text { lakes or mountains. Outdoor activities in natural environments, e.g., camping, } \\
\text { hiking, bird watching. Adult stays in valued natural settings. }\end{array}$ \\
\hline Concern for (grand) children & Aspiration to preserve a healthy environment for future generations. \\
\hline Vocation & Job experiences that initiated or deepened environmental concern or commitment. \\
\hline Principles or religion & $\begin{array}{l}\text { Belief in holiness of nature, or the intrinsic right of its existence. Conviction that } \\
\text { intact ecosystems are crucial. Environmental work as meaningful contribution to a } \\
\text { better world. }\end{array}$ \\
\hline
\end{tabular}

\section{References}

1. Tanner, T. Significant life experiences: A new research area in environmental education. J. Environ. Educ. 1980, 11, 20-24. [CrossRef]

2. James, K. A Qualitative Study of Factors Influencing Racial Diversity in Environmental Education. Ph.D. Thesis, University of Minnesota, Minneapolis, MN, USA, 1993, unpublished.

3. Sward, L.L. Significant life experiences affecting the environmental sensitivity of El Salvadoran environmental professionals. Environ. Educ. Res. 1999, 5, 201-206. [CrossRef]

4. Palmer, J.A. Development of concern for the environment and formative experiences of educators. J. Environ. Educ. 1993, 24, 26-30. [CrossRef]

5. Chawla, L. Life paths into effective environmental action. J. Environ. Educ. 1999, 31, 15-26. [CrossRef]

6. Ganzhorn, J.U.; Lowry, P.P.; Schatz, G.E.; Sommer, S. The biodiversity of Madagascar: One of the world's hottest hotspots on its way out. Oryx 2001, 35, 346-348. [CrossRef]

7. United Nations Development Programme (UNDP). Human Development Report 2015: Work for Human Development. Available online: http://hdr.undp.org/en (accessed on 19 May 2016).

8. Reibelt, L.M.; Richter, T.; Waeber, P.O.; Rakotoarimanana, S.H.N.H.; Jasmin Mantilla-Contreras, J. Environmental education in its infancy at Lake Alaotra, Madagascar. Madag. Conserv. Dev. 2014, 9, 71-82. [CrossRef]

9. Education Policy and Data Center (EPDC). National Education Profile 2014, Update for Madagascar. Available online: http://www.epdc.org/country/madagascar under 'Profiles' (accessed on 10 September 2016). 
10. Waeber, P.O.; Wilmé, L.; Mercier, J.R.; Camara, C.; Lowry, P.P. How effective have thirty years of internationally driven conservation and development efforts been in Madagascar? PLOS ONE 2016, 11, e0161115. [CrossRef] [PubMed]

11. Waeber, P.O.; Reibelt, L.M.; Randriamalala, I.H.; Moser, G.; Raveloarimalala, L.M.; Ralainasolo, F.B.; Ratsimbazafy, J.; Woolaver, L. Local awareness and perceptions: Consequences for conservation of marsh habitat at Lake Alaotra for one of the world's rarest lemurs. Oryx 2017, in press. [CrossRef]

12. Richter, T.; Rendigs, A.; Maminirina, C.P. Conservation messages in Speech Bubbles-Evaluation of an Environmental Education Comic Distributed in Elementary Schools in Madagascar. Sustainability 2015, 7, 8855-8880. [CrossRef]

13. Dolins, F.L.; Jolly, A.; Rasamimanana, H.; Ratsimbazafy, J.; Feistner, A.T.; Ravoavy, F. Conservation education in Madagascar: Three case studies in the biologically diverse island-continent. Am. J. Primatol. 2010, 72 , 391-406. [CrossRef] [PubMed]

14. Ratsimbazafy, J.H. Lemurs as the most appropriate and best didactic tool for teaching. Lemur News 2003, 8, 19-21.

15. Golden, C. Spiritual roots of the land. World Views Environ. Cult. Relig. 2014, 18, 255-268. [CrossRef]

16. Chawla, L. Significant life experiences revisited: A review of research on sources of environmental sensitivity. Environ. Educ. Res. 1998, 4, 369-382. [CrossRef]

17. Chawla, L. Research methods to investigate significant life experiences: Review and recommendations. Environ. Educ. Res. 1998, 4, 383-398. [CrossRef]

18. Palmer, J.A.; Suggate, J. Influences and experiences affecting the pro-environmental behavior of educators. Environ. Educ. Res. 1996, 2, 109-121. [CrossRef]

19. Bandura, A. The psychology of chance encounters and life paths. Am. Psychol. 1982, 37, 747-755. [CrossRef]

20. Wells, N.M.; Lekies, K.S. Nature and the Life Course: Pathways from Childhood Nature Experiences to Adult Environmentalism. Child. Youth Environ. 2006, 16, 1-24.

21. Chawla, L. Learning to love the natural world enough to protect it. Barn 2006, 2, 57-78.

22. Payan, R. How Do We Keep Conservation Alive When Kids Have Less and Less Contact with Nature? Ph.D. Thesis, The University of Arizona, Tucson, AZ, USA, 2012. Available online: http://hdl.handlenet/ 10150/223314 (accessed on 21 November 2016).

23. Mayring, P. Qualitative Inhaltsanalyse; Beltz: Weinheim, Germany, 2003.

24. Lamnek, S. Qualitative Sozialforschung: Lehrbuch; Beltz: Weinheim, Germany, 2005.

25. Scales, I.R. The future of biodiversity conservation and environmental management in Madagascar: Lessons from the past and challenges ahead. In Conservation and Environmental Management in Madagascar; Scales, I.R., Ed.; Routledge: London, UK, 2014; pp. 342-360.

26. Reibelt, L.M.; Nowack, J. Community-based conservation in Madagascar, the 'cure-all' solution? Madag. Conserv. Dev. 2015, 10, 3-5. [CrossRef]

27. Rendigs, A.; Reibelt, L.M.; Ralainasolo, F.B.; Ratsimbazafy, J.H.; Waeber, P.O. Ten years into the marshes-Hapalemur alaotrensis conservation, one step forward and two steps back? Madag. Conserv. Dev. 2015, 10, 13-20. [CrossRef]

28. Simons, E.L.; Meyers, D.M. Folklore and Beliefs about the Aye aye (Daubentonia madagascariensis). Lemur News 2001, 6, 11-16.

29. Lingard, M.; Raharison, N.; Rabakonandrianina, E.; Rakotoarisoa, J.-A.; Elmqvist, T. The role of local taboos in conservation and management of species: The radiated tortoise in southern Madagascar. Conservat. Soc. 2003, 1, 223-246.

30. Mittermeier, R.A.; Tattersall, I.; Konstant, W.R.; Meyers, D.M.; Mast, R.B.; Nash, S.D. Lemurs of Madagascar; Conservation International: Washington, DC, USA, 1994.

31. Ramanantsoa, G.A. The Malagasy and the chameleon: A traditional view of nature. In Key Environments Madagascar; Jolly, A., Oberlé, P., Albignac, R., Eds.; Pergamon Press: Oxford, UK, 1984; pp. 205-210.

32. Chawla, L.; Cushing, D.F. Education for strategic environmental behavior. Environ. Educ. Res. 2007, 13, 437-452. [CrossRef]

33. Palmer, J.A.; Suggate, J.; Bajd, B.; Ho, R.K.; Ofwono-Orecho, J.K.W.; Peries, M.; Robottom, I.; Tsaliki, E.; Van Staden, C. An overview of significant influences and formative experiences on the development of adults' environmental awareness in nine countries. Environ. Educ. Res. 1998, 4, 445-464. [CrossRef] 
34. Stevenson, K.T.; Peterson, M.N.; Carrier, S.J.; Strnad, R.L.; Bondell, H.D.; Kirby-Hathaway, T.; Moore, S.E. Role of significant life experiences in building environmental knowledge and behavior among middle school students. J. Environ. Educ. 2014, 45, 163-177. [CrossRef]

35. Korhonen, K.; Lappalainen, A. Examining the environmental awareness of children and adolescents in the Ranomafana region, Madagascar. Environ. Educ. Res. 2004, 10, 195-216. [CrossRef]

36. Dettmann-Easler, D.; Pease, J.L. Evaluating the effectiveness of residential environmental education programs in fostering positive attitudes toward wildlife. J. Environ. Educ. 1999, 31, 33-39. [CrossRef]

37. Volk, T.L.; Cheak, M.J. The Effects of an Environmental Education Program on Students, Parents, and Community. J. Environ. Educ. 2003, 34, 12-25. [CrossRef]

38. Hsu, S.J. The Effects of an Environmental Education Program on Responsible Environmental Behavior and Associated Environmental Literacy Variables in Taiwanese College Students. J. Environ. Educ. 2004, 35, 37-48. [CrossRef] article distributed under the terms and conditions of the Creative Commons Attribution (CC BY) license (http:/ / creativecommons.org/licenses/by/4.0/). 